\title{
Intonation and Particles as Speech Act Modifiers: A Syntactic Analysis
}

\author{
Johannes Heim, Hermann Keupdjio, Zoe Wai-Man Lam, Adriana Osa- \\ Gómez, Sonja Thoma, and Martina Wiltschko \\ University of British Columbia
}

\begin{abstract}
This study investigates how discourse particles and intonation contribute to the modification of speech act. In particular, it focuses on the interplay between the speaker's and the addressee's commitment toward the proposition in assertions, biased questions, and requests for confirmation. A syntactic analysis is proposed, in which speaker commitment and call on addressee are represented as two functional projections of the speech act structure. Data from nontonal (Canadian English) and tonal languages (Cantonese and Medumba) are analyzed for crosslinguistic comparison. In Canadian English, the particle " $e h$ " and rising intonation are associated with speaker commitment and call on addressee, respectively. In Cantonese, a single particle associates with these. In Medumba, the two positions are occupied by two distinct particles. This neo-performative approach toward speech act structure differs from Ross's 1970 original insight by positing a high functional layer called grounding, rather than a higher matrix clause of the familiar type.
\end{abstract}

\section{Keywords}

syntax, discourse particles, intonation, speech act

Studies in Chinese Linguistics, Volume 37, Number 2, 2016, 109-129 DOI: 10.1515/scl-2016-0005 (C2016 by T.T. Ng Chinese Language Research Centre, Institute of Chinese Studies, The Chinese University of Hong Kong 


\section{Introduction}

This paper explores the grammar of two types of speech act modifiers: particles and sentence intonation, both of which may serve to modify declarative clauses. A formally declarative clause (in canonical subject-verb-object [SVO] order) is typically used as an assertion. It may, however, be modified by either sentence intonation or a sentence-peripheral particle. The result is an utterance, which is associated with a different type of speech act, namely a biased question or a request for confirmation. The second focus of the paper pertains to the cross-linguistic variation that these speech act modifiers display. In particular, we focus on a comparison between tonal and nontonal languages. In tonal languages, particles take over the function of sentence intonation. Finally, the findings motivate a syntactic account of the construction of speech acts. As such, the current analysis contributes to the growing literature, which can be characterized as a revival of Ross's (1970) performative hypothesis. According to this neo-performative view, properties of speech acts and discourse more generally are syntacticized with a fine-grained hierarchy at the left periphery (Speas and Tenny 2003; Hill 2013; Haegeman and Hill 2013; Tang 2015).

Studying speech acts requires the investigation of utterances in context. Most speech acts are directed at an addressee (A), and thus some aspects of the utterance directly reflect an A-orientation. While A-oriented speech is usually found in daily conversations, such conversations are not always the best empirical basis to answer specific research questions for all the familiar reasons, such as the lack of negative data and the lack of controlled context. In the current study, data were collected via controlled storyboard elicitation (Burton and Matthewson 2015), which allows the exploration of the interaction between the speaker (S) and A. In particular, the language consultants were shown a series of pictures (storyboards) that provided enough context for the observer to know how much each of the involved speech act participants already knows about the topic, i.e., it establishes the common ground. The language consultants were asked to say what one of the characters would say (indicated by a speech bubble in the storyboard) - or else whether this character could utter a particular sentence. In this way, storyboards were used as an aid to provide detailed contextual information in elicitation. In standard elicitation tasks, this is done via describing the context orally. However, we found that language consultants find it hard to keep an elaborate context in mind while judging a sentence.

The paper is organized as follows. Section 2 focuses on Canadian English and introduces the empirical problem: declarative clauses may be modified by intonation as well as by means of sentence-peripheral particles. As a result, not only the form of the clause is affected, but it also reflects a change of the discourse context. Section 3 introduces the proposal: the type of speech act modification we observe is analyzed as affecting two distinct syntactic layers dominating the root clause. The first layer is responsible for encoding $S$ commitment, and the second 
layer is responsible for encoding the Call on the Addressee (henceforth CoA) in the sense of Beyssade and Marandin (2006). In the examples from Canadian English discussed in this paper, the $\mathrm{CoA}$ is realized via intonation, whereas $\mathrm{S}$ commitment is modified by sentence-peripheral particles. Each of these strategies is further discussed in the analysis presented in Section 4. Given that sentence intonation is not readily available in tonal languages, the question arises as to how the CoA is encoded in such languages. This question is addressed in Section 5, which discusses the strategies of speech act modification in Cantonese and Medumba. In both languages, particles are used instead of sentence intonation. Section 6 concludes the discussion.

\section{The empirical problem: modified declaratives}

\subsection{Unmarked declaratives: the "I'm telling you" context}

Unmarked declarative clauses are typically used for assertions, as in (1).

(1) Mary, who just got a new dog, runs into Anne, who does not yet know about Mary's dog. Since Mary is so excited about the fact that she has a new dog, she wants to tell Anne right away and utters:

\section{I have a new dog $У$}

The sentence I have a new dog is formally a declarative sentence by virtue of two factors: (i) it has a subject-verb-object (SVO) word order and (ii) it is associated with a falling intonation (indicated by $\mathbf{y}$ ). A typical context for declaratives is characterized by three discourse conditions: (i) $\mathrm{S}$ believes the proposition $(p)$ is conveyed by her utterance (Utt); (ii) A does not already know $p$, and (iii) S wants $\mathrm{A}$ to put $p$ into her set of beliefs (SoB) (Bach and Harnish 1979). Thus, the utterance of a simple declarative can be prefaced with a sentence that expresses S's desire to tell A that $p$, as in (2).

\section{(I have something to tell you) I have a new dog ע}

Henceforth, this type of context is referred to as the "I'm telling you" context.

A simple declarative like (1) can be modified by changing the intonation and by adding a sentence-peripheral particle. Each of these speech act modifiers is discussed in turn.

\subsection{Rising declaratives: the "I don't believe it" context'}

In English, SVO sentences of the form in (1) are not only compatible with falling intonation $(\boldsymbol{V})$ but also with rising intonation ( $(\boldsymbol{)})$. Such sentences are known as rising declaratives (Gunlogson 2003). To see how rising declaratives are used, consider the context in (3).

(3) John mistakenly believes that Anne has a new dog. When he runs into Anne, he asks her how her new dog is doing. Naturally, Anne is confused and responds:

I have a new dog $\nearrow$ 
This is a typical context for rising declaratives. It is characterized by three discourse conditions: (i) $\mathrm{S}$ does not believe $p$ conveyed in $\mathrm{Utt}$; (ii) A seems to believe $p$, and (iii) $\mathrm{S}$ calls on A to confirm that $p$ is true. Thus, the utterance of a rising declarative can be followed by a sentence that expresses S's disbelief, as illustrated in (4).

\section{(4) I have a new dog $\pi$ (I don't think so)}

Henceforth, this type of context is referred to as the "I don't believe it" context.

\subsection{Sentence-final eh: the "Confirm that you know" context}

Finally, simple declaratives of the form in (1) can also be modified by sentencefinal particles such as $e h$ in Canadian English. To see how declaratives modified by $e h$ are used, consider the context in (5).

(5) Mary, who just got a dog, runs into her friend John. Mary cannot remember whether she has already told John that she has a new dog. To be sure, she utters:

\section{I have a new dog, eh $\nearrow$}

This is a typical context for declaratives followed by $e h$. It is characterized by three conditions: (i) $\mathrm{S}$ believes $p$ conveyed in $\mathrm{Utt}$; (ii) $\mathrm{S}$ suspects that A knows $p$, and (iii) $\mathrm{S}$ wants $\mathrm{A}$ to confirm that $\mathrm{A}$ does indeed know $p$. Thus, this utterance can be embedded in a clause that expresses S's suspicion that A already knows $p$.

\section{(6) You know I have a new dog, eh $\pi$}

Henceforth, we refer to this type of context as the "Confirm that you know" context.

Now three types of contexts have been established, which serve as the backdrop for three distinct speech acts which in turn are expressed with three types of clauses. All of them are based on a formally declarative sentence. The change in the discourse conditions reflects a change in the speech act expressed in each of these sentences. This is summarized in Table 1.

Table 1 The three clause types and their respective speech act types

\begin{tabular}{|l|l|l|l|}
\hline Clause-type & $\begin{array}{l}\text { Falling } \\
\text { declarative }\end{array}$ & $\begin{array}{l}\text { Rising } \\
\text { declarative }\end{array}$ & Eh-declarative \\
\hline Speech act & Assertion & $\begin{array}{l}\text { Biased yes/ } \\
\text { no question }\end{array}$ & $\begin{array}{l}\text { Request for } \\
\text { confirmation }\end{array}$ \\
\hline I'm telling you & $\checkmark$ & $x$ & $x$ \\
\hline I don't believe it & $\times$ & $\checkmark$ & $x$ \\
\hline Confirm you know & $\times$ & $x$ & $\checkmark$ \\
\hline
\end{tabular}

The next section addresses the relation between the speech act type and the form of the clause. 


\section{The syntax of speech acts}

The question regarding the relation between the form of the clause and its speech act is a question that lies at the heart of linguistic theory: what is the relation between form and interpretation? Within the realm of phenomena that are clearly identifiable as part of sentence grammar, the answer given within the generative tradition involves recognizing that syntactic structure and computation serves as a mediator between form and interpretation. This is reflected in the fact that within the current minimalist model of the architecture of grammar (i.e., the so-called $\mathrm{Y}$ model), there is no direct relation between PF (form) and LF (interpretation).

Figure 1 The Y model

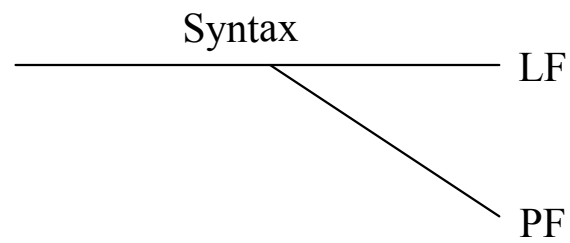

In line with much recent work on the syntax-discourse interface, the current study suggests that the relation between clause-type and speech act type is also mediated by syntax. More precisely, following Ross (1970), each clause is embedded in a larger structure, which is responsible for encoding the discursive interplay between S and A. In the proposal of Ross (1970), this structure was conceived of as a regular matrix clause, roughly paraphrased as I'm telling you that $p$. The current proposal is an update of this hypothesis in that it identifies the embedding structure as the highest functional layer in the extended projection of the clause. This is the structure where speech act properties are encoded. This layer is referred to as the grounding layer.

Following Beyssade and Marandin (2006), modified speech acts are complex. The following section shows that in English, different speech act modifiers are associated with different layers of the clausal architecture. In particular, there are two distinct functional projections in the grounding layer, each associated with a different function. Particles play a role in the expression of the commitment of $\mathrm{S}$ toward what is being said, and intonation plays a role in the expression of the CoA. Thus, following the work of Pierrehumbert and Hirschberg (1990), it is assumed that intonational contours are best analyzed as intonational morphemes (cf. also Truckenbrodt 2012). The particle $e h$ modifies what is being said while the intonational tune modifies the CoA. This is schematized in (7). 
(7) The grounding layer in Canadian English

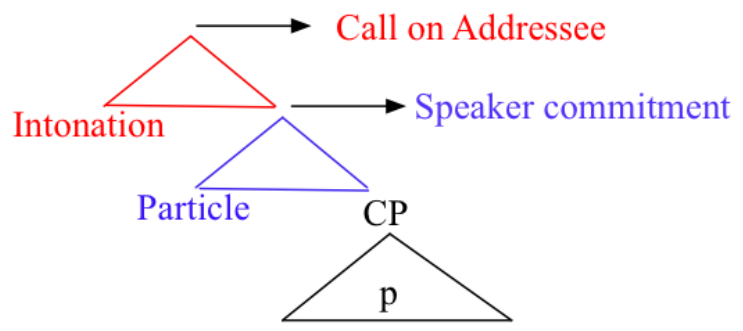

\section{Analysis}

This section demonstrates how the syntactic structure in (7) accounts for the observed modification in speech acts. Recall the discourse conditions for the three types of clauses, as summarized in Table 2.

Table 2 The three clause types and their respective discourse conditions

\begin{tabular}{|l|l|l|l|}
\hline & $\begin{array}{l}\text { Falling } \\
\text { declarative }\end{array}$ & $\begin{array}{l}\text { Rising } \\
\text { declarative }\end{array}$ & Eh-declarative \\
\hline Speech act & Assertion & $\begin{array}{l}\text { Biased yes/no } \\
\text { question }\end{array}$ & $\begin{array}{l}\text { Request for } \\
\text { confirmation }\end{array}$ \\
\hline $\begin{array}{l}\text { S commitment } \\
\text { (What } S \text { says) }\end{array}$ & $p$ is true & $\begin{array}{l}\text { I don't believe/ } \\
\text { know } p\end{array}$ & $\begin{array}{l}\text { I believe that you } \\
\text { believe } p\end{array}$ \\
\hline $\begin{array}{l}\text { CoA } \\
\text { What } S \text { wants } A \text { to do })\end{array}$ & Believe $p$ & $\begin{array}{l}\text { Tell me if } p \text { is } \\
\text { true }\end{array}$ & $\begin{array}{l}\text { Tell me if that is } \\
\text { true }\end{array}$ \\
\hline
\end{tabular}

According to the proposal introduced in Section 3, rising intonation modifies the CoA, whereas the particle $e h$ modifies the $\mathrm{S}$ commitment. The analytical challenge then is to understand why both S commitment and CoA appear to differ in both rising declaratives and in eh-declaratives. In what follows, we show how each of these discourse components is modified by linguistic means. First, Section 4.1 discusses falling declaratives. This establishes the baseline for comparison, since such declaratives are considered unmodified speech acts. It is then followed by the discussion on rising declaratives in Section 4.2 and eh-declaratives in Section 4.3.

4.1 Falling declaratives and the mapping between clause type and speech act

Consider again the "I'm telling you" context, which constitutes the appropriate discourse condition for assertion. The example in (1) has a falling declarative sentence with assertive force. $\mathrm{S}$ is committed to the truth of $p$ and wants $\mathrm{A}$ to believe $p$. Falling declaratives are constructed by means of a declarative clause type (SVO) and falling intonation. Given the proposal in Section 3, the structure in (8) is postulated, where the fall is associated with the layer that encodes the CoA. For details of the assumption that falling intonation is associated with assertive force, see Pierrehumbert and Hirschberg (1990), Bartels (1999), and Truckenbrodt (2013). 
(8) Falling declaratives

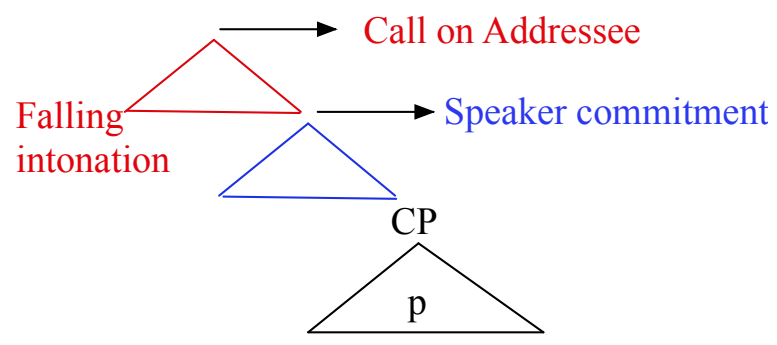

According to the current analysis, S commitment is encoded in the layer of structure occupied by particles. However, in falling declaratives, no particle is present. A felicitous assertion requires $\mathrm{S}$ to be committed to the truth of $p$ (Bach and Harnish 1974). So how does the commitment to the truth of $p$ come about? This is a default interpretation in the context of declarative form in combination with falling intonation. That is, if $\mathrm{S}$ wants $\mathrm{A}$ to believe $p$, as explicitly marked by the falling intonation, then it is implied that $\mathrm{S}$ believes $p$. The assumption that there is, in fact, no explicit encoding of S commitment to $p$ allows us to understand the fact that the same formal clause-type (SVO) is compatible with a question interpretation, namely in the form of rising declaratives.

4.2 Speech act modification by intonation: rising declaratives

Consider again a typical occurrence of a rising declarative, as in (3). Crucially, in this context, $\mathrm{S}$ could not use a falling declarative because the falling declarative commits $\mathrm{S}$ to the truth of $p$. As shown in (9), unlike a rising declarative, a falling declarative cannot be followed by the qualifying statement, which denies S's belief of $p$.

\section{(9) I have a new dog $У$ (\#I don't think so)}

Thus, the effect of the rising intonation in the declarative clause is a biased "yes/ no" question. According to the current analysis, intonation in English operates on the layer of structure responsible for CoA. Hence, a rising intonational morpheme associates at that layer as well, as in (10).

(10) Rising declaratives

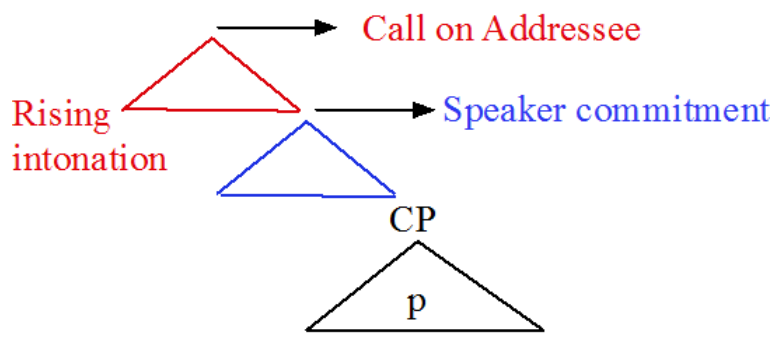


However, as was the case with falling declaratives, no specific marker appears to encode $\mathrm{S}$ commitment. The layer of structure postulated to encode $\mathrm{S}$ commitment is not associated with a particle. This is, in fact, a virtue of the analysis. The fact that $\mathrm{S}$ doesn't believe $p$ is not directly encoded in this utterance. Rather, it is merely a discourse context that is compatible with this utterance along with a series of other contexts, including one where $\mathrm{S}$ has no attitude toward $p$ (neither belief nor disbelief). To see this, consider the following context.

(11) Mary knows that Anne wanted to get a new dog for a while. They haven't seen each other for a few weeks and Mary thinks that Anne may have gotten that dog by now, but she is not sure. Next time they see each other the conversation goes as follows.

Anne: Guess what....

Mary: You got a new dog $\nearrow$ I wasn't sure whether you did, that's why I didn't bring any treats.

In (11), Mary has no commitment toward $p$ and the rising declarative is still possible. This is consistent with the assumption that $\mathrm{S}$ commitment is not explicitly encoded. Similarly, rising declaratives are also compatible with a context where $\mathrm{S}$ not only has no commitment to $p$, but $p$ has not even entered her ground. Consider the context below.

(12) Mary's best friend Anne just got a new dog but Mary doesn't know that. Next time they see each other, the conversation goes as follows.

Mary: How are you doing?

Anne: Great. I love my new dog!

Mary: You got a new dog $\boldsymbol{\lambda}$ (I had no idea)

In (12), Mary first hears about Anne's new dog at the current discourse. After Anne's declaration that she loves her new dog, Mary can utter a rising declarative, followed by a sentence that indicates that this $p$ has not entered her ground until the current conversation.

In sum, rising declaratives are compatible with any context in which $\mathrm{S}$ is not committed to the truth of $p$. This is the case if $\mathrm{S}$ does not believe in $p$, or if $\mathrm{S}$ does not know whether or not $p$ is true, or else if $\mathrm{p}$ is not in S's ground. The only context that is not compatible with a rising declarative is one where $\mathrm{S}$ is committed to the truth of $p$. Thus, a rising declarative is incompatible with the "confirm that you know" context as shown in (13).

(13) Mary got a new dog. Mary runs into her friend John. Mary cannot remember whether she has already told John that she has a new dog. So, she utters:

\#I have a new dog $\pi$

As a consequence, a rising declarative cannot be followed by a sentence that asserts $\mathrm{S}$ is committed to the truth of $p$, as in (14).

(14) You have a new dog $\nearrow$ (\#I knew that already) 
This establishes that the declarative clause type is not intrinsically associated with a marker of S commitment. Instead, S commitment can be inferred based on sentence intonation, which in turn encodes the CoA. Falling intonation encodes that $\mathrm{S}$ wants A to believe $p$ (and thus $\mathrm{A}$ can infer that $\mathrm{S}$ believes $p$ ). In contrast, rising intonation encodes that $\mathrm{S}$ wants $\mathrm{A}$ to respond to the utterance by revealing her commitment to $p$. Thus, rising declaratives shift the commitment from $\mathrm{S}$ to A (Gunlogson 2003).

\subsection{Modification by particles}

In this subsection, the focus is switched to the second speech act modifier, namely the particle $e h$. Consider the context in (15).

(15) Mary got a new dog. She runs into her friend John. Mary cannot remember whether she has already told him that she has a new dog. So, she utters:

I have a new dog, eh $\pi$

The utterance in (15) consists of a declarative clause followed by the particle $e h$, which is sometimes classified as a discourse marker or an invariant tag. In (15), eh modifies the speech act, such that the utterance does not function as a declarative, but as a request for confirmation. Hence, $e h$ and similar particles are referred to as confirmationals.

Interestingly, in (15), the request for confirmation concerns not the truth of $p$ but whether A knows $p$. Thus, in this situation, the simple declarative is modified in two ways. First, eh introduces S's belief about A's belief, thereby creating a complex proposition ( $\left.p^{\prime}\right)$. Second, $\mathrm{S}$ asks A to confirm that this complex $p$ [Adr $(\mathrm{Bel}, \mathrm{p})]_{\mathrm{p}}$, is, in fact, true. This question is asked by virtue of introducing the polar opposite alternative $(\operatorname{not} p){ }^{1}$

This analysis correctly predicts that $e h$ is incompatible with any context in which $\mathrm{S}$ knows that A does not believe or know $p$. Thus, an eh-declarative cannot be marked as being surprising to $A$, as in (16).

a. \# Guess what, I have a new dog, eh $\lambda$

b. \# Surprise, I have a new dog, eh $\nearrow$

Moreover, if it is clear from the context that A does not know $p$, then the use of $e h$ is predictably infelicitous, as for example in (17).

(17) A: You will never get a dog again

B: \# But I have a new dog, eh $\pi$

\footnotetext{
1 For reasons of space, we cannot fully introduce and justify this assumption. It is consistent with standard semantic treatments of yes/no questions in terms of introducing set of alternatives (i.e., the polar opposite; Hamblin (1973), Karttunen (1977), and Groenendijk and Stokhof (1982)). Furthermore, it is consistent with the lexicalization patterns of confirmationals. That is, several languages use as their confirmationals either polar response particles (e.g., Spanish si, no) or the disjunctive conjunction (German oder). See Yang and Wiltschko (2016) for further discussion.
} 
Thus, with the use of $e h$, both $\mathrm{S}$ commitment and the CoA are being modified. Consequently, this speech act modifier is expected to be complex, which is indeed the case. In particular, the particle associates with the layer responsible for encoding S commitment, whereas rising intonation - in this case realized on the particle rather than the whole clause - associates with the layer of structure responsible for encoding CoA. This is illustrated in (18). ${ }^{2}$

(18) Eh-declaratives

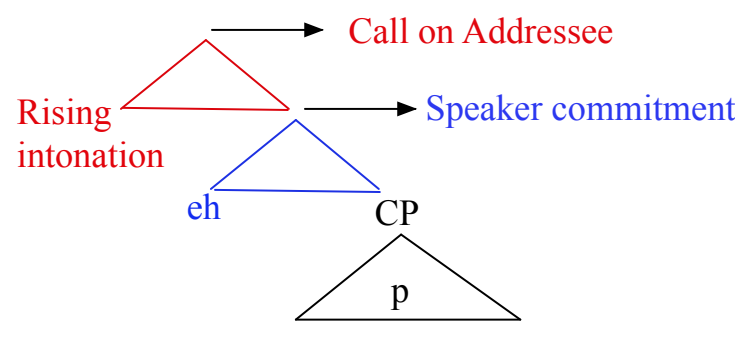

This analysis predicts that both rising intonation and the particle can appear independently. The previous subsection has already shown that rising intonation does indeed occur without the particle, namely in the form of a rising declarative. In addition, it is observed that $e h$ can be used without rising intonation, namely in the form of the so-called narrative use of $e h$ (Avis 1972; Johnson 1976). This use of $e h$ is illustrated by instances of $e h$ in (19).

(19) So I go to this shrink, $\boldsymbol{e h}$, and he goes like I don't have no confidence, $\boldsymbol{e h}$. I go, 'No way, man.' He goes I should take assertiveness training. Weird, eh $\boldsymbol{\lambda}$ Like I'm always supposed to be seeking approval, eh, from, you know, other people? I felt like he could kiss my Royal Canadian, eh $\pi$ But, sayin' it wouldabeen too pushy. Dyuh think?

(Casselman 2015)

The narrative use of $e h$ is often characterized as having level intonation (Avis 1972) and the fact that $\mathrm{S}$ does not expect a response from $\mathrm{A}$. While the intonation contour of the conformational eh is fully rising (Figure 2), the intonation contour of the narrative $e h$ is flat (Figure 3) (Derek, Wiltschko and d'Arcy 2016). ${ }^{3}$

Note crucially that the particle still expresses the idea that $\mathrm{S}$ believes that $\mathrm{A}$ believes in $p$. In this case, this belief comes about because $\mathrm{S}$ just told $\mathrm{A}$ about $p$, and has therefore legitimate reason to believe that $\mathrm{A}$ believes $p$. The rising intonation

2 We are not claiming that all instances of intonational tunes are associated with the Call on Addressee (see Wakefield (2012) for an example of intonation being associated with the epistemic state of the speaker (our speaker commitment).

3 The intonational contours if Figures 2 and 3 are those of data from the Urban Dialectology 2015 SLX interviews (Denis 2015). 
additionally asks A for confirmation that this is indeed so, whereas the absence of the rise indicates that $\mathrm{S}$ will still continue to talk. ${ }^{4}$

Figure 2 Intonational contour of confirmational $\mathrm{eh}$

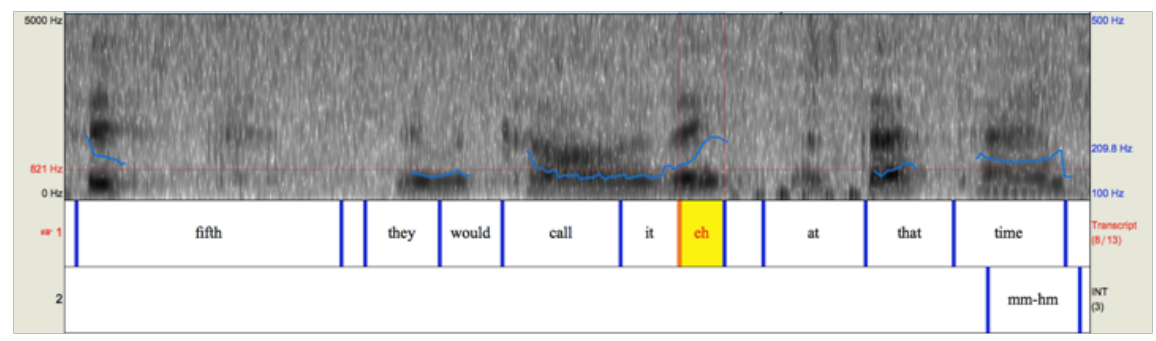

Figure 3 Intonational contour of narrative $e h$

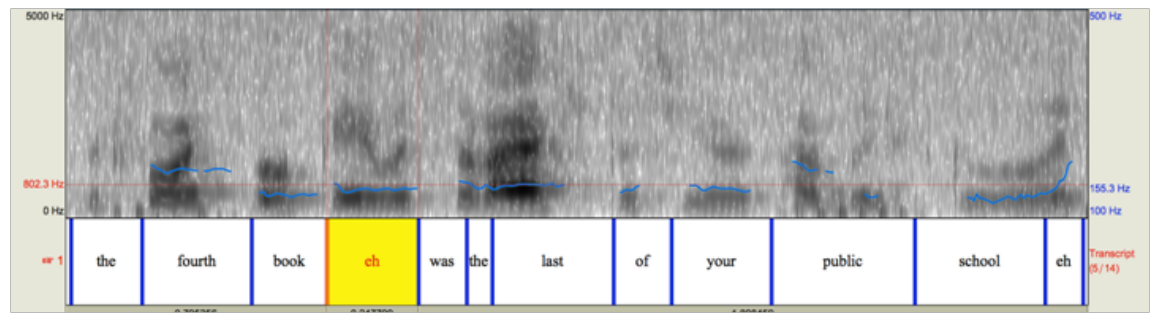

In sum, independent evidence has been presented for the decomposition of the speech act modifier $e h$ into its lexical contribution (as a modifier of what is being said) and its intonational contour (as a modifier of the CoA). On the one hand, eh can occur with rising intonation, resulting in a request for confirmation, or with level intonation, resulting in the so-called narrative $e h$. The independence of intonation from the particle is further supported by the fact that rising intonation can co-occur with formally declarative clauses to produce biased questions, as discussed in Section 4.2.

\section{Cross-linguistic variation in speech act modification}

The previous section has established that both particles and intonation, and the combination of the two, can modify speech acts. A declarative sentence with falling intonation is interpreted as an assertion; a declarative sentence with rising intonation is interpreted as a biased question; a declarative sentence followed by the particle $e h$, which is itself associated with rising intonation, is interpreted as a request for confirmation. The fact that sentence intonation can serve as a speech act modifier raises an important question regarding cross-linguistic variation. In

4 Similar patterns are also found in Spanish (Adriana Osa Gomez, p.c.), and in German dialects (Wiltschko and Heim, to appear). 
tonal languages, lexical contrast and intonation compete for the same resource, namely pitch, to convey information. Hence there is less room available for speakers to manipulate pitch for sentence intonation. This raises the question as to whether there are similar types of speech act modifiers in tonal languages?

\subsection{Cantonese}

Although Canadian eh can combine with either a rising or falling intonation, it is not the case for particles in Cantonese, a Sinitic language with six lexical tones and a huge inventory of sentence-final particles (SFPs). In many studies of Cantonese SFPs, it is assumed that SFPs share the same functions as intonation in English. Wakefield (2010) presents empirical evidence to support this impressionistic claim by conducting translation tasks with Cantonese/English native bilinguals. He finds that some Cantonese SFPs have English intonational counterparts. One implication of his results echoes with the current analysis - intonation should have a morphemic status, just like SFPs. In another phonetic study, Zhang (2014) finds that Cantonese SFPs and sentence-final intonation are in complementary distribution. As she points out, when a sentence has a segmental SFP, the SFP performs the function of expressing intonation. When a sentence does not contain any segmental SFP, extraordinary patterns of pitch, nor sentence-final intonation, it can be referred to as a "segmentless SFP."

Since segmental particles and sentence-final intonation (or segmentless SFPs) never co-occur in Cantonese, the following analysis posits that $\mathrm{S}$ commitment and the CoA are simultaneously encoded by a single particle in Cantonese. ${ }^{5}$ Thus this is an instance of a single exponent spanning over more than on functional head (see Williams 2003 and Svenonius 2012 for the notion of a span). Consider the "I'm telling you" context, where $\mathrm{S}$ uses a simple unmodified declarative to convey that he or she believes in $p$, and that he or she wants A to also believe in $p$. Just like in English, the "I' $m$ telling you" context is characterized by an unmarked clause, as in (20).

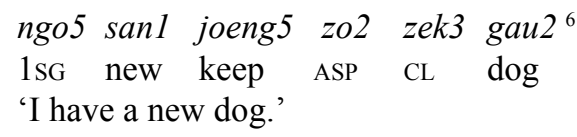

Next, consider the "I don't believe it" context, where English uses a rising declarative. In Cantonese, this sentence is modified by a right-peripheral particle $m e 1$, as shown in (21).

\footnotetext{
5 It remains a debate whether the tone of the particle is a tonal morpheme (see discussion of Sybesma and Li 2007) or intonation (see Wu 2008), and how the segmental and suprasegmental elements associate with $\mathrm{S}$ and/or CoA. We leave this for future research.

6 The use of the particle $a a 3$ at the end of this sentence will enhance the naturalness of this utterance. For a detailed discussion of the meaning of $a a 3$, see Leung (2008). Since $a a 3$ does not change the clause type of the sentence and it is not the focus of this paper, it is omitted in this example to highlight the contrast between (20), (21), and (23).
} 
(21)
$\begin{array}{lllllll}\text { mat1 ngo5 } & \text { san1 } & \text { joeng5 zo2 } & \text { zek3 } & \text { gau2 } & \text { me1? } \\ \text { what } 1 \mathrm{SG} & \text { new } & \text { keep ASP } & \text { CL } & \text { dog } & \text { PRT }\end{array}$
'What, I have a new dog?! (But I don't!)'

There is a crucial difference between rising declaratives in English, and the use of Cantonese mel. Recall that rising declaratives are not explicitly encoding that $\mathrm{S}$ is committed to believing not $p$. Instead, the "I don't believe it" context is just one of the three contexts that is compatible with rising declaratives. Cantonese mel differs in this respect, in that it explicitly commits $\mathrm{S}$ to believing not $p$. It can be concluded that the particle mel associates with $\mathrm{S}$ commitment as well as the CoA, as in (22).

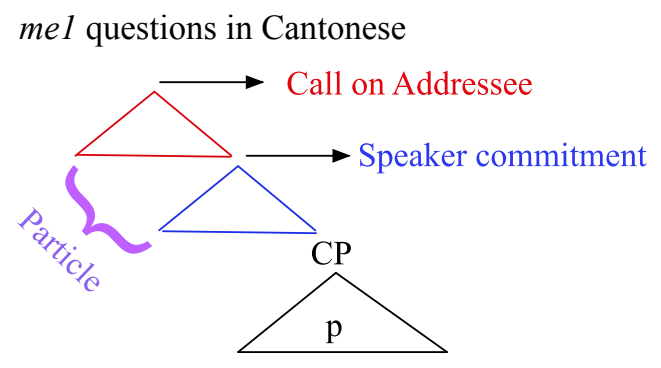

Finally, consider the "Confirm that you know" context, where English uses a particle in combination with sentence intonation, being realized on the particle rather than the clause, as in (18). In this context, Cantonese uses a single particle, namely ho2, as shown in (23).

$$
\begin{aligned}
& \text { nei5 san1 joeng5 zo2 zek3 gau2 ho2? } \\
& \text { 2SG new keep ASP CL dog PRT } \\
& \text { 'You have a new dog, eh?' }
\end{aligned}
$$

Cantonese ho2 modifies what is being said as well as the CoA. In particular, with the use of ho2, S expresses his or her assumption about A's belief toward the truth of $p$, and calls on A to confirm whether this assumption is true. Given the analysis developed thus far, it can be concluded that the Cantonese particle ho2, just like mel, spans across two syntactic heads.

The case of Cantonese shows that in a tonal language, where intonation is not as readily available to modify speech acts, particles can fulfill the same function. This conclusion is not surprising, in light of the assumption that sentence intonation associates with the syntactic tree in the same way as any other morpheme. If indeed one particle associates with both positions in Cantonese, we predict that there are languages having two separate particles encoding each of $\mathrm{S}$ commitment and CoA. This is indeed the case in Medumba, another tonal language. 


\subsection{Medumba}

Medumba is a Grassfields' Bamileke Bantu language with lexical tone. To modify speech acts, this language uses particles. In particular, Medumba has particles that modify $\mathrm{S}$ commitment (what is being said) as well as particles that modify the CoA (what S wants A to do). Consider the "I'm telling you" context in (24).

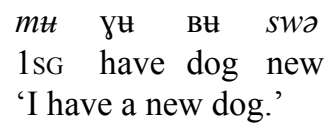

Just as in English, assertions in Medumba are formed by unmarked declaratives. No particles are used in this context. This contrasts with the other two contexts under investigation. First, consider the "I don't believe it" context, where English uses rising declaratives. In Medumba, this change in speech act is encoded by means of two separate but homophonous sentence-final particles, as shown in (25).

$$
\begin{aligned}
& m H \text { yH } \mathrm{BH} \text { swa } \boldsymbol{a} \quad \boldsymbol{a} \text { ? } \\
& \text { 1SG have dog new PART Q } \\
& \text { 'I have a new dog?' }
\end{aligned}
$$

As indicated by the glosses, the first occurrence of $a$ encodes that $\mathrm{S}$ commits to the belief not $p$, while the second occurrence of $a$ changes the CoA to request a response. ${ }^{7}$ Thus, the sentence in (25), is a biased "yes/no" question where S is committed to not believe $p$.

Finally, consider the third context of investigation, namely the "Confirm that you know" context. S expresses that she believes that A believes $p$ and simultaneously requests A to confirm whether this is indeed the case. S's attitude toward $p$ is expressed by the sentence-initial particle ktla whereas the CoA is expressed by the particle $a$.

(26) kula $u$ ун вн swa a?

PART 2SG have dog new Q

'You have a new dog, eh?'

Thus, according to the current analysis, Medumba is a language where both the layer dedicated to encoding the $\mathrm{CoA}$, as well as the layer dedicated to encoding $\mathrm{S}$ commitment, are associated with one particle, as in (27).

\footnotetext{
7 Our reason to believe that there are in fact two particles, which sound the same $(a)$ as opposed to one particle (i.e., a long vowel $a$ ) is as follows. First, vowel length is not contrastive in Medumba. Second, other instances of long vowels in Medumba are realized with rising tone ( $\breve{a})$, whereas the particle combination in (25) is phonetically realized as a long vowel bearing mid tone (a).
} 


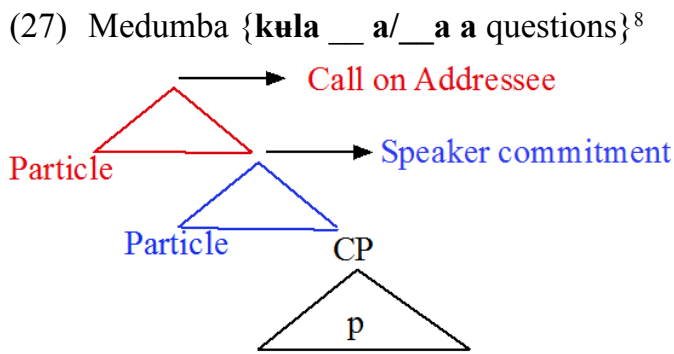

\section{Conclusion}

This paper has explored how speech acts can be modified by means of sentence intonation and particles. The data from the three contexts have shown that speech acts can be modified in two ways: first, the content of $\mathrm{S}$ commitment can be modified, and as a result, what is being said differs from a typical declarative. The content can be changed in two ways: either $\mathrm{S}$ can commit to not believing $p$, or else, $\mathrm{S}$ can commit to a proposition different from $p$, namely the proposition that A believes $p$. Second, the nature of the CoA can be modified, resulting in differences in what $\mathrm{S}$ expects from A. For example, in an unmarked declarative, $\mathrm{S}$ wants $\mathrm{A}$ to believe $p$. This contrasts with sentences where $\mathrm{S}$ wants $\mathrm{A}$ to respond with her assessment of the truth of $p$. The proposed analysis is couched within a syntactic framework which takes the syntactic spine to be intrinsically associated with universal functions (Wiltschko 2014). The highest layer of the spine is responsible for encoding discourse-sensitive notions such as $\mathrm{S}$ commitment and $\mathrm{CoA}$. This assumption is in line with several proposals, which aim to syntacticize discourse (Speas and Tenny 2003; Haegeman and Hill 2013; Tang 2015). These recent analyses can be viewed as a revival of Ross's 1970 performative hypothesis, according to which every matrix clause is embedded in another clause, which encodes the speech act. Thus, a typical assertion would actually be embedded in a higher matrix clause, roughly paraphrased as "I'm telling you that p." In the course of the derivation, this matrix clause is deleted. A similar analysis has recently been suggested by Kayne (2016) for sentence final particles such as right or again as in (28) and (29).

(28) We're on the list, right?

Kayne 2016: 4 (3)

(29) Where do they live, again?

Kayne 2016: 6 (12)

8 The question remains as to how to derive the linear ordering of sentence final particles. In particular, why do some particles appear sentence-initially while others appear sentence-finally, even within the same language. Keupdjio and Wiltschko (2016) develop an analysis in terms of movement. 
Kayne (2016) argues that right and again are merged inside complex phrases (isn't that right/tell me again) with a silent ISN'T THAT/TELL ME as in (30) and (31), where capital letters indicate non-pronunciation. ${ }^{9}$

(30) We're on the list, ISN'T THAT right?

(31) Where do the live TELL ME again?

Note that the core insight of Kayne's analysis is compatible with the proposal developed here: the silent phrases isn't that right and tell me again encode a question or command, which roughly correspond to the CoA in our terms.

There are, however, several reasons to reject the particular implementation of Kayne's analysis. First, it assumes the SFP is embedded in a regular propositional structure. Hence, Kayne's analysis has much in common with Ross's 1970 original performative hypothesis. But this makes it vulnerable to precisely the same criticism, which ultimately lead to the dismissal of the performative hypothesis (see Anderson 1971, among many others). For example, this analysis cannot rule out recursion. In particular, on Kayne's analysis it is unclear why the two SFPs cannot co-occur:
a. *We're on the list, right, again?
b. *We're on the list, again, right?

A second reason to reject Kayne's analysis for SFPs is, in general, the fact that some of these particles do not have a double life as a main predicate and hence cannot straightforwardly embedded in the kind of silent propositional structure Kayne proposes. This is the case for $e h$ as well as $h u h$, both of which can function as SFPs and function in similar ways as right as shown in (33). However, they cannot be embedded in the equivalent propositional structure, as shown in (34).

(33) a. We're on the list, right?

b. We're on the list, eh?

c. We're on the list, huh?

(34) a. We're on the list, isn't that right?

b. *We're on the list, isn't that eh?

c. *We're on the list, isn't that huh?

This suggests that $e h$, and $h u h$ are indeed particles that modify speech acts without the support of propositional structure. Finally, note that right can be used as a

\footnotetext{
9 Kayne's (2016) main motivation behind this analysis is theory-internal: there are reasons to assume that heads are always silent and hence sentence-final particles cannot be merged as heads. While we do not adopt Kayne's specific proposal regarding SFPs for empirical reasons (see above), our analysis is compatible with assuming that SFPs are merged as phrases. In particular, if we assume that SFPs are propositional anaphors in the sense of Krifka (2013), then we can analyse them as phrases which associate with the specifier positions in the articulated speech act phrase.
} 
SFP without corresponding to what would be paraphrased by the propositional structure (isn't that right). Consider the example in (35). In this example, right is not used to express 'isn't it right that I know that' (Derek, Wiltschko and d'Arcy 2016).

(35) I know, right?

Hence we reject Kayne's (2016) analysis of SFPs on empirical grounds.

The recent reincarnations of the performative hypothesis no longer treat the embedding structure as a regular propositional structure; instead, the embedding structure consists of functional categories only. For example, in Speas and Tenny's (2003) version of the speech act phrase, it is considered to be a ditransitive predicate which can roughly be paraphrased as $S$ gives $p$ to $A$, as schematized in (36).

The speech act phrase

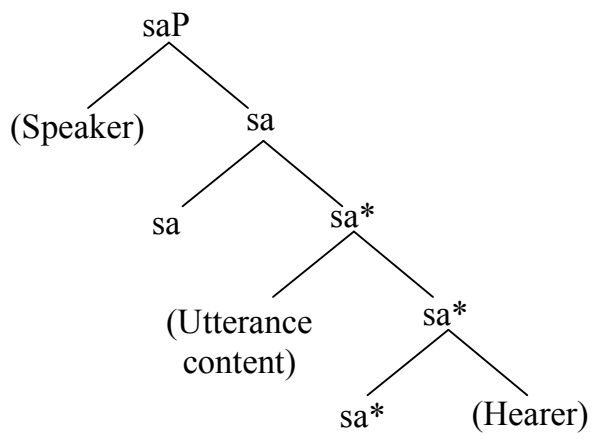

Speas and Tenny (2003:320)

The current analysis differs from previous ones in that it locates the argument representing A higher than that representing S (cf. Lam 2014). ${ }^{10}$ A piece of important evidence for this order comes from the fact that the modification of $\mathrm{S}$ commitment must occur before the modification of CoA. This is supported by the fact that in the presence of the particle $e h$, rising intonation must associate with this particle and cannot associate with the sentence as a whole. If $e h$ attaches before rising intonation, rising intonation has to be realized on the next available phonological string. If rising intonation were attached before $e h$, then we would expect that it be realized on the sentence with subsequent addition of the particle.

${ }^{10}$ Lam (2014) postulates to distinct layers where commitment to $\mathrm{p}$ can be modified: one that is S-oriented and one that is A-oriented (Thoma (2016) and Wiltschko (to appear)). Thus there are two A-oriented layers in the articulated speech act structure: one that is responsible for encoding how S evaluates A's commitment to p (Lam (2014), Force-A and Wiltschko's small groundP) and one that is responsible for encoding the Call on Addressee (not discussed in Lam and Wiltschko (to appear), Resp(onse)P). 
Furthermore, the classic assumption that $\mathrm{S}$ must be higher than $\mathrm{A}$ is grounded in the assumption that the speech act of assertion can be paraphrased as $S$ gives $p$ to $A$. However, as illustrated in this paper, speech acts are more complex than that. While some contexts show that this is indeed the case (i.e., the "I'm telling you" context), there are other contexts showing that it is not always the case. Such contexts are characterized by the fact that S puts $p$ out for A to consider and wants A to respond, to see whether $p$ should indeed be adopted in the set of beliefs. This process is sometimes referred to as tabelling (Malamoud and Stephenson 2014). Thus, only if A accepts $p$, will $p$ enter the common ground (Stalnaker 2002). This is compatible with the structural configuration in which $\mathrm{S}$ is lower than $\mathrm{A}$ : first, $\mathrm{S}$ says something and then $\mathrm{s} / \mathrm{he}$ gets A to respond to what is being said.

We conclude that a neo-performative analysis of the type suggested here is empirically superior to a revival of the performative analysis.

\section{Acknowledgments}

The research reported here was funded by a SSHRC Insight Grant awarded to Martina Wiltschko. We thank the audience at the Canadian Linguistics Association as well as the members of the eh-lab (http://syntaxofspeechacts.linguistics.ubc.ca) for helpful discussion.

\section{References}

Anderson, Stephen R. 1971. On the linguistic status of the performative/constative distinction. Bloomington: Indiana University Linguistics Club.

Avis, Walter. S. 1972. So eh? is Canadian, eh. Canadian journal of linguistics 17(2). 89-104.

Bach, Kent \& Robert Harnish. 1979. Linguistic communication and speech acts. Cambridge, MA: MIT press.

Bartels Christine. 1999. The intonation of English statements and questions. New York: Garland Publishing.

Beyssade, Claire \& Jean-Marie Marandin. 2006. The speech act assignment problem revisited: Disentangling speaker's commitment from speaker's call on addressee. In Selected Papers of CSSP 2005, 37-68. http://www.cssp.cnrs.fr/eiss6/index_ en.html.

Burton, Strang \& Lisa Matthewson. 2015. Targeted construction storyboards in semantic fieldwork. In Ryan Bochnak \& Lisa Matthewson (eds.), Methodologies in semantic fieldwork. Oxford: Oxford University Press.

Casselman, Bill. 2015. The true story of a Canadian interjection $e$ ? http://www.billcasse Iman.com/casselmania/mania_eh.htm.

Columbus, Georgie. 2010. A comparative analysis of invariant tags in three varieties of English. English World-Wide 31(3). 288-310.

Denis, Derek 2015. The development of pragmatic markers in Canadian English. Unpublished PhD dissertation, University of Toronto.

Denis, Derek, Martina Wiltschko \& Alex d'Arcy. 2016. Deconstructed multi- 
functionality: Confirmational variation in Canadian English through time. Talk presented at DiPVaC3, University of Ottawa. May.

Groenendijk, Jeroen \& Martin Stokhof. 1984. On the semantics of questions and the pragmatics of answers. Varieties of formal semantics 3. 143-170.

Gunlogson, Christine. 2013. True to form: Rising and falling declaratives as questions in English. New York: Routledge.

Haegeman, Liliane \& Virginia Hill. 2013. The syntactization of discourse. In Raffaella Folli, Christina Sevdali \& Robert Truswell (eds.), Syntax and its limits, 370-390. Oxford: Oxford University Press.

Hamblin, Charles L. 1973. Questions in Montague English. Foundations of language. 41-53.

Hill, Virginia. 2013. Vocatives: How syntax meets with pragmatics. Leiden: Brill.

Johnson, Marion. 1976. Canadian eh. Ohio State University Working Papers in Linguistics 21. 153-160.

Kaiser, Sebastian \& Stefan Baumann. 2013. Satzmodus und die Diskurspartikel hm: Intonation und interpretation. Linguistische Berichte 236. 473-496.

Karttunen, Lauri. 1977. Syntax and semantics of questions. Linguistics and philosophy 1(1). 3-44.

Kayne, Richard. 2016. The silence of heads. Studies in Chinese Linguistics 37(1). 1-37

Krifka, Manfred. 2013. Response particles as propositional anaphors. In Todd Snider (ed.), Proceedings of Semantics and Linguistic Theory (SALT) 23, 1-18. Ithaca NY: CLC Publications.

Lam, Zoe Wai-Man. 2014. A complex forceP for speaker- and addressee-oriented discourse particles in Cantonese. Studies in Chinese Linguistics 35(2). 61-80.

Leung, Wai Mun. 2008. Promising approaches for the analysis of sentence-final particles in Cantonese. Asian Social Science 4(5). 74-82.

Malamud, Sophia A. \& Tamina C. Stephenson. Three ways to avoid commitments: Declarative force modifiers in the conversational scoreboard. Journal of Semantics 31. 1-37.

Pierrehumbert, Janet \& Julia Hirschberg. 1990. The Meaning of intonational contours in the interpretation of discourse. In Philip R. Cohen, Jerry Morgan \& Martha E. Pollack (eds.), Intentions in communication, 271-311. Cambridge, Mass.: MIT Press.

Ross, John R. 1970. On declarative sentences. In Roderick A. Jacobs \& Peter S. Rosenbaum (eds.), Readings in English transformational grammar, 222-272. Waltham, Mass.: Ginn \& Co.

Sadock, Jerrold M. 1974. Toward a linguistic theory of speech acts. New York: Academic Press.

Sadock, Jerrold M. \& Arnold M. Zwicky. 1985. Sentence types. In Timothy Shopen (ed.) Language Typology and Syntactic Description. Volume 1, Clause structure, 155-96. Cambridge: Cambridge University Press.

Speas, Peggy \& Carol Tenny. 2003. Configurational properties of point of view roles. In Anne-Marie Di Sciullo (ed.), Asymmetry in Grammar. Volume 1, Syntax and semantics, 315-343. Amsterdam: John Benjamins. 
Svenonius, Peter. 2012. Spanning. Ms., University of Tromsø. http://ling.auf.net/ lingBuzz/001501.

Stalnaker, Robert. 2002. Common ground. Linguistics and Philosophy 25(5). 701-721. Sybesma, Rint \& Boya Li. 2007. The dissection and structural mapping of Cantonese sentence final particles. Lingua 117(10). 1739-1783.

Tang, Sze-Wing. 2015. Cartographic syntax of pragmatic projections. In Audrey Li, Andrew Simpson \& Wei-tien Dylan Tsai (eds.), Chinese Syntax in a CrossLinguistic Perspective, 429-441. Oxford \& New York: Oxford University Press.

Thoma, Sonja. 2016. Discourse particles and the syntax of discourse. Evidence from Miesbach Bavarian. Unpublished $\mathrm{PhD}$ dissertation, University of British Columbia.

Truckenbrodt, Hubert. 2012. Semantics of intonation. In Klaus von Heusinger, Claudia Maienborn \& Paul Portner (eds.), Semantics. An international handbook of natural language meaning. Berlin; Boston: De Gruyter Mouton.

Wakefield, John. 2010. The English equivalents of Cantonese sentence-final particles: A contrastive analysis. Hong Kong: The Hong Kong Polytechnic University dissertation.

Wiltschko, Martina. 2014. The universal structure of categories: Towards a formal typology. Cambridge, United Kingdom: Cambridge University Press.

Wiltschko, Martina. To appear. Ergative constellations in the structure of speech acts. In Jessica Coon, Diane Massam \& Lisa deMena Travis (eds.), The Oxford handbook of ergativity. New York: Oxford University Press.

Wiltschko, Martina \& Johannes Heim. To appear. The syntax of sentence peripheral discourse markers. Towards a neo-performative analysis.

Williams, Edwin. 2003. Representation theory. Cambridge, Mass.: MIT Press.

Wu, Wing-Li. 2008. An acoustic phonetic study of the intonation of sentence-final particles in Hong Kong Cantonese. Asian Social Science 4(2). 23-29.

Zhang, Ling. 2014. Segmentless sentence-final particles in Cantonese: An experimental study. Studies in Chinese Linguistics 35(2). 47-60.

Address: Department of Linguistics, 2613 West Mall, Vancouver BC V6T1Z4, Canada

Email: Martina.Wiltschko@ubc.ca

Received: February 23, 2015

Accepted: June 22, 2016 


\title{
語調和話語助詞作為言語行為修飾詞的句法分析
}

\author{
Johannes Heim 、Hermann Keupdjio 、林慧雯、 \\ Adriana Osa-Gómez 、Sonja Thoma、Martina Wiltschko \\ 英屬哥倫比亞大學
}

\section{提要}

本文探討話語助詞和語調如何修飾言語行為。我們透過陳述句、含偏見的問句和要 求確認句, 分析說話者和受話者對命題的承擔程度, 以及兩者之間的互動。在我們 所提出的句法分析中, 言語行為的結構由兩個功能投射所組成, 分別為 “說話者的 承擔程度” 和 “邀請受話者回應”。為了比較不同語言的相關現象, 我們的語料包 括非聲調語言（加拿大英語）和聲調語言（粵語和喀麥隆的麥中巴語）。在加拿大 英語中, 話語助詞 $e h$ 佔據 “說話者的承擔程度” 的位置, 而向上的語調則屬 “邀 請受話者回應” 的位置。在粵語, 一個話語助詞可以同時佔據兩個位置。在麥中巴 語, 這兩個位置分別由兩個不同的話語助詞佔據。本文對言語行為的分析與 Ross （1970）的表述句式假說有別。Ross 提出更高層的主句, 但該句仍屬既有的種類； 本文提出的是更高層的功能投射, 稱為 “grounding”。

\section{關鍵詞}

句法學, 話語助詞, 語調, 言語行為 